\title{
Bir Kolonoskopi Gerçeği: Utanma Duygusu ve Yönetimi
}

A Colonoscopy Fact: The Feeling of Embarrassment and Its Management

\author{
Semra ERDAĞI ORAL ${ }^{1}$, Nadiye ÖZER ${ }^{2}$
}

\begin{abstract}
ÖZ
Kolonoskopi günümüzde başta kolorektal kanserlerin tarama ve tanısı olmak üzere pek çok hastalıkta yaygın olarak uygulanmaktadır. Vücudun en mahrem bölgelerinden biri olarak kabul edilen anorektal bölgeden yapılan kolonoskopi gibi işlemler ve muayenelerin hastaları küçük düşürdüğüne dair ön yargılı fikirler vardır. $\mathrm{Bu}$ fikirler hastada utanma duygusu oluşturarak hastayı rahatsız edeceğinden ve işlemin başarısını olumsuz yönde etkileyebileceğinden bu duygunun yönetilerek en aza indirilmesi önemlidir. Kolonoskopi işleminden utanan bireyler için hasta eğitimi ve danışmanlığı gibi müdahaleler bireyin utanma duygusunu azaltarak hasta konforunun artmasına, işleme uyum sağlamasına, kolorektal kanser taramalarına daha fazla kişinin katılımı sağlanarak kolorektal kanserlerin erken dönemde tanılanmasına katkı sağlar. $\mathrm{Bu}$ derleme; kolonoskopi uygulanan hastaların yaşadıkları potansiyel utanma nedenlerini literatür incelenmesiyle belirlemek, hemşireleri utanma duygusu yönetimi hakkında bilgilendirmek ve farkındalıklarını artırmak amacıyla yazılmıştır.
\end{abstract}

Anahtar Kelimeler: Hemşirelik, Kolonoskopi, Utanma, Yönetim.

\begin{abstract}
Today, colonoscopy is widely used in many diseases, especially in the screening and diagnosis of colorectal cancers. There are prejudiced ideas stating that procedures and examinations such as colonoscopy from the anorectal region which is regarded as one of the most intimate areas of that body, humiliate patients. Because these ideas will disturb the patient by creating a feeling of embarrassment in the patient and may adversely affect the success of the procedure, it is important to manage and minimize this emotion. Interventions, such as patient education and counseling for individuals feeling embarrassed due to colonoscopy procedure, decrease the feeling of embarrassment, increase patient comfort, facilitate adherence to the procedure, provide the participation of more people in colorectal cancer screening, and thus make contribution to early diagnosis of colorectal cancers. The aim of this review is to determine the potential reasons of embarrassment of the patients, who undergo colonoscopy, upon literature review, to inform nurses about management of embarrassment, and increase their awareness.
\end{abstract}

Keywords: Colonoscopy, Embarrassment, Nursing, Management. 


\section{GİRIS}

Kolonoskopi günümüzde başta kolorektal kanserlerin tarama ve tanısı olmak üzere pek çok hastalıkta yaygın olarak uygulanmaktadır. Bağırsak şikayeti ve demir eksikliği olan hastalarda, kolonda anormal bulguları olan hastaların ve kolon kanseri için pozitif tarama test sonucu olan hastaların ayırıcı tanısında ve yangısal bağırsak hastalığı takibinde kullanılan en iyi yöntemdir. ${ }^{1}$

Kolonoskopinin hem kolorektal kanser önleme programlarında tarama yöntemi hem de çeşitli hastalıklarda tanı tedavi ve izlem yöntemi olarak kullanılması birçok ülkede kolonoskopi yapılma sıklığını artırmaktadır. ${ }^{2}$ Kolonoskopi sık başvurulan invaziv girişim olmasına rağmen birçok ülkede hastaların kolonoskopiye uyum gösterme oranının düşük ve kolonoskopi işleminin hastalar üzerinde olumsuz etkileri olduğu belirtilmektedir. ${ }^{2}$

\section{Kolonoskopinin Hastalar Üzerindeki Etkileri}

Kolonoskopinin hastalar üzerindeki olumsuz etkileri, işleme uyumsuzluk, isteksizlik ve işlem sonrası olumsuz deneyim olarak değerlendirilebilir. Girişimin bu kavramlarla değerlendirilmesine, bağırsak temizliği, uzun süre aynı pozisyonda hareketsiz kalma gibi fiziksel faktörler; rahatsız edici pozisyon, mahremiyetin ortadan kalktığ1 düşüncesi yüzünden işlemi kabullenmekte güçlük yaşama gibi psikolojik faktörler ve kişinin değer inançları neden olmaktadır. ${ }^{3-5} \quad$ Yapılan çalışmalarda; kolonoskopi uygulanan hastaların çoğunlukla utanma duygusu yaşadıkları tekrar kolonoskopi yaptırmaları istenirse bir daha işlemi yaptırmayı düşünmedikleri ve kolonoskopinin yerine kullanılabilecek alternatif başka bir yöntem arayışına girdikleri tarama programlarını dikkate almadıkları ve işlemi erteledikleri belirlenmiştir. ${ }^{4,6-10}$ Ayrıca hastaların kötü bir tanı konulması korkusu ve buna bağlı anksiyete deneyimlediklerini ve uygulama öncesi bağırsak hazırlık aşaması nedeniyle iğrenme, tiksinti duyma gibi olumsuz duygulara kapıldıklarını saptayan çalışmalar da bulunmaktadır. ${ }^{2,6,10}$
Kolonoskopi işlemi sırasında vücudun mahrem bölgesinin el ve gözlem yolu ile incelenmesi, mahrem bölgeye girişimsel işlem uygulanması, sağlık profesyonelinin mahrem beden bölgesine dokunması, cilt kusurları, şişmanlık gibi beden imajının olumsuz algılandığ1 durumlarda bedenin bir başkası tarafından görülmesi, hastanın değer ve inançları gibi unsurlar utanma nedenleridir. ${ }^{5,11-14}$

Yapılan çalışmalar, utanma duygusu ile kolonoskopi işlemini yaptırma isteksizliği arasında pozitif yönde bir ilişki olduğu yönündedir. ${ }^{8,14}$ Bajracharya ve arkadaşları (2017) kolonoskopi yaptıran ve yaptırmayan kişilerle gerçekleştirdikleri çalışmada; girişim uygulanmayan kişilerin \%29'unun işlemi utanmaya neden olacak bir test olarak belirtirken, girişim uygulanan kişilerde bu oran \%69 olarak bulunmuştur. ${ }^{9}$ Yakut ve arkadaşlarının (2009) Türk insanının kolonoskopiye bakış ve uyumunu inceledikleri çalışmada, eğitim seviyesi ile utanma duygusu arasında pozitif yönde bir ilişki olduğu saptanmış; 104 hastadan 34'ü işlem tekrar gerekirse hiçbir koşulda işlemi yaptırmayacağını ifade etmiş ve sadece 8 hastanın rutin kolorektal tarama için başvurduğu belirlenmiştir. ${ }^{15}$ Aynı çalışmada hastaların büyük çoğunluğu işlemi psikolojik olarak kabullenilmesi zor bir işlem şeklinde tanımlamıştır. ${ }^{15}$

Kolonoskopi uygulamasına yaklaşımda değer ve inanç sistemi de rol oynamaktadır. ${ }^{5}$ Greiner ve arkadaşlarının (2005) kolorektal kanser taramalarıyla ilgili çalışmasında; bu tarama yöntemine ilişkin araştırmaya katılanların utanma duygusu yaşadıkları ve düşüncelerini " $\mathrm{Bu}$ utanç verici bir test. İnsanların inançlarına ters olan bir işlem, eğer İncil'i okursanız, rektuma herhangi bir şeyin girmesine izin verilmez." şeklinde ifade ettikleri görülmüştür. ${ }^{5}$

Kolonoskopi gibi kolorektal kanser taramalarının hem erkekler hem de kadınlar tarafindan utanmaya yol açtığ erkekler genellikle sağlık çalışanlarından utandıklarını direkt olarak ifade etmemektedirler. Erkekler taramalar 
hakkında olumsuz düşüncelerini bastırmakta kadınlar ise çekincelerini daha açık ifade etmektedirler. $^{7} \quad$ Friedemann-Sánchez ve Partin'in (2007) yaptığı çalışmada kadınlar kolonoskopi sırasında yaşadıkları fiziksel rahatsızlığın yanı sira duygusal rahatsızlıktan bahsetmişlerdir. Kıyafetlerini çıkarıp yan yattıkları zaman odada bulunan insanların onların vücutlarına bakacakları düşüncesi kadınlarda utanmaya yol açmıştır. Erkekler ise daha çok yaşadıkları ağrı gibi fiziksel rahatsızlıklardan bahsetmişlerdir. ${ }^{4}$ Çalışmadaki kadın hastalar yaşadıkları anksiyete, korku ve utanma gibi duygusal savunmasızlık nedeniyle sedatif ilaç isterken, erkek hastalar ağrı nedeniyle sedatif ilaç istemişlerdir. ${ }^{4}$ Goldman ve arkadaşlarının Dominik ve Porto Riko'da bireylerin kolorektal kanser tarama algılarını incelediği çalışmada, kadınların çılak bölgelerine doktor tarafindan dokunulması ve gözlenmesinden dolayı utandıklarını bulunmuştur. ${ }^{11}$ Green ve Kelly'nin (2004) çalıșmasında kadın katılımcıların \% 73,8'inin kolonoskopi gibi taramaları utanma nedeniyle yaptırmadığ 1 bulunmuştur. ${ }^{8}$ Menees tarafından yapılan çalışmada kadın hastaların yarıya yakını utanma nedeniyle bir kadın endoskopiste kolonoskopi yaptırabilmek için 30 günden fazla bekleyebileceklerini ifade etmişlerdir. ${ }^{16}$

\section{Kolonoskopide Utanma Duygusu Yönetimi ve Hemşirelik}

Kolonoskopinin hastalar/bireyler üzerindeki utanma gibi olumsuz etkileri, hastaların tanı ve tedavi yöntemlerinden kaçınarak kronik sorunlar yaşamalarına yol açmaktadır. $^{10-12} \mathrm{Bu}$ nedenle utanma kavramını anlamak ve kolonoskopi işlemi ile ilgili utanma duygusunu yönetmek son derece önemlidir. Utanma duygusunu yönetebilmek için öncelikle bu duyguyu anlamak gerekir. Utanma kişinin kendi benliği ile ilişkili olduğundan bireyin tek başına bununla baş etmesi zordur. ${ }^{17}$ Utanma strese benzer sonuçlar ortaya çıkaran, değiştirilebilir bir durum olarak düşünülmektedir. İnsanların utanma duygularını azaltmak büyük çaba gerektirebilir. $^{18,19}$ Utandığını kabul eden bireylerle, utanma hakkında konuşmak utanmay1 azaltabilir. ${ }^{16}$

Vücudun en mahrem bölgelerinden biri olarak kabul edilen anorektal bölgeden yapılan kolonoskopi gibi işlemler ve muayenelerin hastaları küçük düşürdüğüne dair ön yargılı fikirler vardır. Bu fikirler hastada utanma duygusu oluşturarak hastayı rahatsız edeceğinden ve işlemin başarısını olumsuz yönde etkileyebileceğinden bu duygunun yönetilerek en aza indirilmesi önemlidir. ${ }^{20}$

Kolonoskopi işlemi için bireyin bilgilendirilmesi, işleme hazırlanması ve işlem sırası, sonrası takibi endoskopi hemşireliği içinde yer alan kolonoskopi hemşiresinin görev yetki ve sorumlulukları arasındadır. $^{21,22}$ Hastayı işleme hazırlama, hemşirelik yaklaşımının en önemli yönüdür. Hemşire hastayı hem fiziksel hem de psikolojik olarak kolonoskopi için hazırlamalıdır. ${ }^{23}$

Kolonoskopi hemşiresi potansiyel utanmaya neden olan kaynakları bilmeli ve bu kaynaklar içinde kontrol altına alınabileceklere yönelik girişimleri belirlemelidir. İşleme özel müdahaleler geliştirmesinin yanı sıra kişiye işlem hakkında bilgi vermek, bütüncül yaklaşımla işleme hazırlamak ve işlem sırası bakımı sürdürmek, hasta konforunu ve memnuniyetini artırarak kolonoskopiye uyum geliştirilmesinde önemlidir. $22,24,25$

Utanma duygusunun kolonoskopi yaptıran kiși tarafından tanımlanabilmesi için, ișlem öncesinde kolonoskopi hemşiresinin hastaların işlem hakkındaki düşüncelerini ve duygularını sözel olarak ifade etmeye cesaretlendirecek ortamı hazırlaması gerekir. ${ }^{24}$ Hastada utanma duygusunu; yüzde kızarma ve göz temasından kaçınma gibi utanmanın evrensel belirtilerinin yanında hastanın sürekli özür dilemesi, hareketlerinin artmas1, terlemesi, konuyu örtbas etmesi veya değiștirmesi gibi belirtiler de düșündürür. Hemşire bu belirtilerin farkında olmalıdır. ${ }^{26}$ Ayrica meslekte utanma duygusunun yönetimi yaş ve deneyimle birlikte daha kolay olabilir. Deneyim, hemşireye kendisini teknik olarak beceri anlamında daha yetkin 
hissetmesini sağlamanın yanında daha geniş bir bilgi ve güven duygusu oluşturur, bu da utanmayı daha yönetilebilir hale getirir. ${ }^{27}$

Kolonoskopi işleminde utanma kaynaklarının başında mahremiyet duygusunun azalması ya da kaybı gelebilir. ${ }^{28}$ Hemşire kolonoskopi işleminde hastanın utanma duygusunu azaltmak için mahremiyete özen göstermelidir. Beden mahremiyetine özen gösterilmesi özel yaşama saygının gereğidir ve ihlal edildiğinde kişi psikolojik yönden örselenebilir. Hasta Hakları Yönetmeliğinin 21. maddesinin "Mahremiyete Saygı Gösterilmesi" başlığının altında yer alan: "Muayenenin, teşhisin, tedavinin ve hasta ile doğrudan teması gerektiren diğer işlemlerin makul bir gizlilik ortamında gerçekleştirilmesi gerekir", "Hasta, tedavisi ile doğrudan ilgili olmayan kimselerin, tıbbi müdahale sırasında bulunmamasını isteyebilir" fikraları doğrudan beden mahremiyetine özeni hükme bağlamıştır. $\mathrm{Bu}$ nedenle kolonoskopi gibi, hastaların utanmalarına yol açan işlemlerde hastanın tedavisi ile doğrudan ilgili olmayanların tıbbi müdahale sirasinda bulunması gerekli ise; önceden veya işlem sırasında bunun için hastadan ayrica rızası alınmalıdır. ${ }^{29,30}$ Hastanın rızasını almak, hastada mahremiyetine sayg1 gösterildiğini, kendisine değer verildiğini düşündürür ve kendini ifade etmesine olanak sağlayabilir. ${ }^{30}$ Girişim uygulanırken odada sadece görevli sağlık çalışanlarının bulunması, işi olmayan insanların herhangi bir nedenle odaya girmemesi, işlem sırasında kapının kilitli olması hastanın kendisini daha iyi hissetmesine neden olur. ${ }^{30}$ Rosenwasser ve arkadaşları kırsal bölgede çalışan birinci basamak hekimlerinin bakış açısıyla kolorektal kanser taramalarına yönelik engelleri inceledikleri çalışmada; hekimler özellikle küçük bölgelerde yaşayan kadınların kolonoskopi odasinda bulunacak olan insanları tanıyor olabileceği ihtimalinden ötürü erkeklerden daha çok utanma yaşadıklarını belirtmişlerdir. ${ }^{31}$

Literatürde; endoskopi odasının durumu, işlem için giyilen kıyafet, işlemin yapılacağı pozisyon, işlem sırasında etkileşimde bulunulan sağlık çalışanının tutumu, gibi pek çok faktörün hastanın utanma ve memnuniyetinde önemli olduğu belirtilmektedir. $^{32}$

Hastaların hazırlandığ $\breve{1}_{1}$ odada, kolonoskopi şortu ve bone gibi giysilerini hastaların mahremiyetlerini koruyarak giymelerini sağlanmalıdır. Hastaların kolonoskopi gibi işlemler için hazırlanması durumunda, sadece minimum kiyafetler çıkarılmalı ve vücudun geri kalan kısımlarının mahremiyeti sağlanmalıdır. ${ }^{30} \mathrm{Bu}$ amaçla hastalar için işlem sırasında mutlaka kalça bölgesini kapatan, bedenine uygun, sadece anüs bölgesini açık bırakan örtü ya da kolonoskopi şortu kullanılmalıdır. ${ }^{33}$ Hastanın bedenine uygun olmayan giysiler hastalarda mahremiyet kaybına yol açar. ${ }^{30}$ Hemşireler hastaların hazırlandığı odada, kolonoskopi şortu ve bone gibi giysilerini hastaların mahremiyetlerini koruyarak giymelerini sağlamalıdır. ${ }^{30}$ Aamar ve arkadaşları (2017) kolonoskopi sirasinda hastaların mahremiyetini korumak için özel pantolon giydirdikleri çalışmada; hastaların çoğu bu pantolonunun kolonoskopi sirasinda fiziksel mahremiyet korumasını artırdığını, işlemden daha az utandıklarını ve kendilerini daha saygın hissettiklerini belirtmişlerdir. ${ }^{26}$

Kolonoskopi odasında hemşireler, hastaların işlem için masaya alınmasına, mahremiyetine dikkat ederek uygun pozisyonun verilmesine ve işlem süresince hasta güvenliğini sağlayarak işlemin uygulanmasına yardım etmelidirler. Ayrıca bu süreçte hemşireler hastaları psikososyal açıdan desteklemelidir. ${ }^{21-23}$ Yapılan çalışmalarda hasta için bilinmezliklerle dolu olan kolonoskopi ünitesinde hastanın işlem hakkında sağlık çalışanları tarafından yeterli ve doğru bilgilendirilmesinin, işlem prosedürlerini öğrenmesinin, hastanın ön yargısını ve utanma duygusunu azalttığı, işleme uyumunu kolaylaştırdığı bildirilmektedir. ${ }^{34,35} \quad$ Sewitch ve arkadaşlarının (2013) kolonoskopi hizmetleri için hasta tarafından belirlenen kalite göstergeleri çalışmasında hastalar kolonoskopiyi oldukça utanç verici bir işlem olarak değerlendirmiş, kolonoskopideki en 
önemli durumun gizlilik olduğunu, kolonoskopi ekibinin mahremiyeti sağlarken kendileriyle konuşmalarının ve bilgi vermelerinin onları rahatlattığını ifade etmişlerdir. $^{35}$

İşlem tamamlandıktan sonra hasta dinlenme odasına alınırken mahremiyetine dikkat edilmeli ve odada yatak başı perdeleri kapalı olmalıdır. ${ }^{34}$ Sewitch ve arkadaşlarının çalışmasında (2013) hastalar işlem sonrası çok fazla gazları olduğu için utandıklarını ve dinlenme odasinda mutlaka yatak kenarlarındaki perdelerin çekilmesi gerektiğini ifade etmişlerdir. ${ }^{35}$

\section{Utanma Yönetimi İçin Kullanılabilecek Eğitim Araçları}

İşlem öncesi hemşireler kolonoskopi girişimi gereken hastalarda farklı eğitim yöntemleri ile utanma duygusunu yönetebilirler. ${ }^{35}$ Literatürde; kolonoskopi uygulamasında hastaların sağlık çalışanlarının verdiği bilgileri genellikle unuttukları ya da yanlış anladıkları; bu nedenle hastalara eğitim verilirken broşür ve video kullanılması önerilmektedir. ${ }^{36}$ Kolonoskopi prosedürü ile ilgili broşür/eğitim kitapçı̆̆ı ve video kullanılarak verilen eğitimlerin hastaların rahatsızlık, anksiyete ve utanma gibi duygusal engellerini azalttığ 1 bildirilmektedir. ${ }^{37-39}$ Liu ve arkadaşları (2011) kolorektal kanser tarama prosedürleri hakkında bireylere yazılı bilgi verdikten sonra tutumlarını inceledikleri çalışmada; bireylerin utanma duygularının çok yüksek olmadığı belirlenmiştir. ${ }^{40}$ Shaikh ve arkadaşları (2010) eğitim broşürünün kolon kanseri taraması üzerine etkisini inceledikleri çalışmada; elektronik e-posta ile Amerikan Gastroenteroloji Derneği eğitim broşürünü gönderdikleri hastaların, genel anksiyete düzeyinin daha düşük, işlem sırasında sedatif kullanımının daha az olduğu saptanmıştır. $^{37}$

Kolonoskopi uygulamasında hasta eğitimi için kullanılan bir başka yöntem video ile eğitimdir. ${ }^{36}$ Kolonoskopi öncesinde video ile bilgi verilen çalışmalarda, video ile bilgi verilmesinin hastaların işlem sırasında ilaç gereksinimlerini ve anksiyetesini azalttığ1, psikolojik olarak hastayı rahatlattığı vurgulanmıştır. ${ }^{38}$ Arabul ve arkadaşlarının (2012) kolonoskopi öncesinde video ile bilgilendirmenin hasta tatmini ve anksiyete üzerine etkisini inceledikleri çalıșmada; video ile bilgilendirmenin işlem başarısını olumlu etkilediği ve anksiyeteyi azalttığ1 saptanmıştır. $^{38}$ Erdağı Oral'ın (2018) çalışmasında kolonoskopi uygulanan hastalara eğitim kitapçığ 1 ve video ile verilen planlı eğitim programlarının hastaların utanma duygusunu azalttı̆̆ saptanmıştır. ${ }^{39}$

\section{SONUÇ VE ÖNERILER}

Kolonoskopi gibi beden odaklı taramalarda sağlık çalışanlarının/hemşirenin hastanın utanma nedenlerini tartışması hastanın işlemden kaçınmasına engel olarak utanma yönetimine katkı sağlayabilir. Kolonoskopi işleminden utanan bireyler için hasta eğitimi ve danışmanlığı gibi müdahalelerin bireyin utanma duygusunu azaltarak hasta konforunun artmasına, işleme uyum sağlamasına ve kolorektal kanser taramalarına katılımının artırılmasına destek olacağı düşünülmektedir.

KAYNAKLAR

1. Hazewinkel Y, Dekker E. (2011). "Colonoscopy: basic principles and novel techniques." Nature reviews Gastroenterology \&Hepatology, 8 (10), 554-564.

2. Gipsh K, Sullivan JM, Dietz EO. (2004). "Health belief assessment regarding screening colonoscopy.' Gastroenterol Nurs, 27 (6), 262-267.

3. Dillard AJ, Fagerlin A, Dal Cin S, Zikmund-Fisher BJ, Ubel PA. (2010). "Narratives that address affective forecasting errors reduce perceived barriers to colorectal cancer screening." Soc Sci Med, 71 (1), 45-52.
4. Friedemann-Sanchez GGJ, Partin MR. (2007). "Gender differences in colorectal cancer screening barriers and information needs." Health Expect, 10 (2), 148-160.

5. Greiner KA, Born W, Nollen N, Ahluwalia JS. (2005). "Knowledge and perceptions of colorectal cancer screening among urban African Americans." J Gen Intern Med, 20 (11), 977-983.

6. Trevisani L, Zelante A, Sartori S. (2014). "Colonoscopy, pain and fears: Is it an indissoluble trinomial?." World J Gastroentero, 6 (6), 227-233. 
7. Ritvo P, Myers RE, Paszat L, Serenity M, Perez DF, Rabeneck L. (2013). "Gender differences in attitudes impeding colorectal cancer screening." BMC Public Health, 13 (1), 500-515

8. Green PM, Kelly BA. (2004). "Colorectal cancer knowledge, perceptions, and behaviors in African.' Americans. Cancer Nurs, 27 (3), 206-215.

9. Bajracharya SM. (2017). "Knowledge, perceived benefits, and barriers of college employees regarding colorectal cancer (CRC) screening: a replication study." Intern J Health, Well Soc, 7 (2), 88-95.

10. Attarabeen OF, Sambamoorthi U, Larkin KT, Kelly KM (2018). "Colon cancer worry in Appalachia." J Commun Health, 43 (1), 79-88.

11. Goldman RE, Diaz JA, Kim I. (2009). "Perspectives of colorectal cancer risk and screening among Dominicans and Puerto Ricans: stigma and misperceptions." Qual Health Res, 19 (11), 1559-1568.

12. Consedine NS, Ladwig I, Reddig MK, Broadbent EA. (2011). "The many faeces of colorectal cancer screening embarrassment: Preliminary psychometric development and links to screening outcome." Brit J Health Psych, 16 (3), 559-579.

13. Condon A, Graff L, Elliot L, Ilnyckyj A. (2008), "Acceptance of colonoscopy requires more than test tolerance.” Can J Gastroenterol, 22 (1), 41-47.

14. Bynum SA, Davis JL, Green BL, Katz RV. (2012). "Unwillingness to participate in colorectal cancer screening: examining fears, attitudes, and medical mistrust in an ethnically diverse sample of adults 50 years and older.” Am J Health Promot, 26 (5), 295-300

Yakut M, Uysal E, Beşik G, Özkan Y, Kırbaş G, Özden A. (2009). "Türk insanı kolonoskopi işlemine nasıl bakıyor? Kolonoskopi hazırlık rejimine uyumu etkileyen faktörlerin irdelenmesi: Klinik prospektif çalıșma." Endoskopi Derg, 17 (2): 69-71.

16. Menees SB, Inadomi JM, Korsnes S, Elta GH. (2005). "Women patients' preference for women physicians is a barrier to colon cancer screening." Gastrointest Endosc, $62(2), 219-223$

17. Wilson J. (2001). "Shame, guilt and moral education." J Moral Educ, 30 (1), 71-81

18. Krishna A, Herd B, Aydınoğlu NZ. (2015). "Wetting the bed at twenty-one: Embarrassment as a private emotion." J Consum Psychol, 25 (3), 473-486.

19. Mitchell KA, Rawl SM, Champion VL, Jeffries PR, Welch JL. (2012). "Development and psychometric testing of the colonoscopy embarrassment scale." Western J Nurs Res, 34 (4), 548-564.

20. Marsicovetere P. (2018). "Examining, diagnosing, and treating benign anorectal conditions." J Am Acad Pas, 31 (3), 32-37.

21. Erdil F, Elbaş NÖ. (2008). Cerrahi Hastalıklar Hemșireliği Genișletilmiş V. Baskı, Ankara: Aydoğdu Ofset Matbacilık, 447-450.

22. Öztekin SD. (2007) Endoskopi Hemşireliğine Giriş, 1. Baskı, Ankara, Alter Yayınc1lık, 114-150

23. Lewis SM, Heitkemper MM, Dirksen SR. (2004). "Medical-surgical nursing: assessment and management of clinical problems." 6th ed. Publishing: Mosby, 182183
24. Mitchell KA, (2009). Development and Psychometric Testing of the Colonoscopy Embarrassment Scale, PhD Thesis, School of Nursing, Bloomington: Indiana University.

25. Condon A, Graff L, Elliot L, Ilnyckyj A. (2008). "Acceptance of colonoscopy requires more than test tolerance.” Can J Gastroenterol, 22 (1) ,41-47.

26. Aamar A, Madhani K, Butt Z, Ali I, Aslanian HR. (2017). "Privacy pants in colonoscopy: a novel approach to enhance colon cancer screening." Gastrointest Endosc, 85 (5), 268

27. Lawler J. (2004). Embarresment Social Rules and Context of Body Care. In: Blaikie A, Hepworth M, Holmes M, Howson A, Inglis D, Sartain S (Eds). The Body Critical Concepts in Sociology, 1thed. Psychology Press, 418-438.

28. Deryal Y. (2008). Hastanın Özel Yaşamana Sayg Hakkının İki Boyutu: Hasta Sırrının Korunması ve Beden Mahremiyeti, Ankara Üniversitesi Hukuk Fakültesi Sağlık Kurultayı, Ankara Barosu Yayınları, Ankara, 7184.

Hasta Hakları Yönetmeliği,
https://www.saglik.gov.tr/TR,10461/hasta-haklariyonetmeligi.html, (Erişim tarihi: 28 /06/2020).

30. Baillie L. (2009). "Patient dignity in an acute hospital setting: a case study.” Int J Nurs Stud, , 46 (1), 22-36.

31. Rosenwasser LA, McCall-Hosenfeld JS, Weisman CS Hillemeier MM, Perry AN, Chuang CH. (2013). "Barriers to colorectal cancer screening among women in rural central Pennsylvania: Primary care physicians' perspective.” Rural Remote Health, 13 (4), 2504-2517.

32. Chung SH, Park SJ, Hong JS, , Hwang JY, Lee SA, Kim KR et. el. (2013). "Comparison of double pants with single pants on satisfaction with colonoscopy." World J Gastroentero, 19 (26), 4177-4184

33. Marsicovetere P. (2018). Examining, diagnosing, and treating benign anorectal conditions." J Am Acad Pas, 31 (3), 32-37.

34. Brandt LJ. (2001). "Patients' attitudes andapprehensions about endoscopy: how to calm troubled waters." Am J Gastroenterol, 96 (2), 280-284

35. Sewitch MJ, Dubé C, Brien S, Jiang M, Hilsden RJ, Barkun AN, Armstrong D. (2013). "Patient-identified quality indicators for colonoscopy" services. Can J Gastroenterol, 27 (1), 25-32.

36. Davis TC, Dolan NC, Ferreira MR, Tomori C, Green KW, Sipler AM., Bennett CL. (2001)." The role of inadequate health literacy skills in colorectal cancer screening." Cancer Invest, 19 (2), 193-200.

37. Shaikh AA, Hussain SM, Rahn S, Desilets DJ. (2010). "Effect of an educational pamphlet on colon cancer screening: a randomized, prospective trial." Eur J Gastroen Hepat, 22 (4), 444-449.

38. Arabul M, Kandemır A, Celik M, et.el. (2011).'Impact of an information video before colonoscopy on patient satisfaction and anxiety." Turk J Gastroenterol, 23 (5), 523-529.

39. Erdağı Oral S. (2018). Kolonoskopi Uygulanan Hastalarda Beden İmajı Algısı ve Farklı Eğitim Programlarının Utanma Duygusuna Etkisi. Atatürk Üniversitesi Sağlık Bilimleri Enstitüsü Doktora Tezi.

40. Liu CJ, Fleck T, Goldfarb J, Green C, Porter, E. (2011). "Attitudes to colorectal cancer screening after reading the prevention information.” J Cancer Educ, 26 (4),701-707. 